\title{
OS INDICADORES DE TRABALHO DECENTE NO AMBIENTE CORPORATIVO DAS MULHERES NA POLÍCIA CIVIL DO ESTADO DO RIO GRANDE DO SUL
}

Data de submissão: 10/11/2017 Aceite: 22/03/2018

\author{
Sérgio Rossi Madruga ${ }^{1}$ \\ Lúcia Rejane da Rosa Gama Madruga² \\ Marcelo Mendes Arigony ${ }^{3}$
}

\section{RESUMO}

Este estudo aborda o trabalho da mulher na Polícia Civil do Estado do Rio Grande do Sul, sob a ótica dos critérios do Trabalho Decente da Organização Internacional do Trabalho. A pesquisa classificase no campo da sustentabilidade, na vertente social, relacionada à responsabilidade social corporativa, em busca da necessária gestão pública sustentável. O objetivo foi analisar o ambiente para as mulheres, com base nos critérios do trabalho decente. A coleta de dados foi realizada a partir de diversas fontes de evidência, fazendo-se uso de dados primários e secundários. O estudo tem natureza qualitativa, a partir de um roteiro de observação e um instrumento flexível composto por perguntas abertas. A interpretação foi realizada utilizando-se de procedimento de análise de conteúdo, com foco nas oportunidades que a mulher passou a encontrar a partir da década de 1970 e, atualmente, ocupa lugar destacado em paridade com os homens, não obstante, com algumas evidências de limitação de oportunidades. A percepção geral é de desconformidade com os indicadores da OIT, ressalvando-se os critérios ligados à seguridade e diálogo social, assim como estabilidade e rendimento, que foram considerados total ou parcialmente atendidos. Nos demais pontos não há adequação do trabalho policial aos vetores da OIT, especialmente segurança, igualdade, oportunidades, conciliação e jornada de trabalho.

Palavras-chave: Trabalho Decente. Responsabilidade Social. Indicadores de Trabalho Decente. Sustentabilidade Social.

\footnotetext{
1 Possui graduação em Ciências Contábeis pela Universidade Federal de Santa Maria, UFSM, mestrado em Administração pela Universidade Federal de Santa Catarina, UFSC, doutorado em Administração pela Universidade de São Paulo, USP. Santa Maria - RS - Brasil. E-mail: smadruga2010@gmail.com

2 Possui graduação em Licenciatura Plena Em Matemática pela Antiga Faculdade Imaculada Conceição Hoje Denominada Centro Universitário F, FIC, graduação em Administração pela Universidade Federal de Santa Maria, UFSM, mestrado em Engenharia de Produção pela UFSM, doutorado em Agronegócios pela Universidade Federal do Rio Grande do Sul, UFRGS. Santa Maria - RS - Brasil. E-mail: luciagm@ufsm.br 3 Possui graduação em Direito pela Universidade Federal de Santa Maria, UFSM, mestrado em Administração pela UFSM, doutorado em andamento em Administração pela UFSM. Santa Maria - RS - Brasil. E-mail: marceloarigony@hotmail.com
} 


\section{INTRODUÇÃO}

A organização social encontra seu núcleo central no trabalho, que traz sentido existencial e contribui para a estruturação da personalidade e identidade do indivíduo, de forma a propiciar subsistência e trazer riqueza social. O conceito é baseado em Borges e Tamayo (2001), e serve de introdução à temática relativa ao trabalho da mulher policial, marco de um novo paradigma relacionado ao feminino.

O trabalho feminino passou a ocupar importante parcela da indústria, o que inclusive fomentou a criação de legislação protetiva específica ao gênero feminino, para preservação do trabalho doméstico e da dupla jornada, inerente ao gênero feminino. Assim surgiram licença-maternidade, limitação de trabalho noturno e restrição de jornada semanal de trabalho (ALVESSON; BILLING, 1997).

Para Moraes (2002), o que a Constituição veda são as diferenciações arbitrárias, as discriminações odiosas, pois o tratamento desigual aos desiguais, na medida em que se desigualam, é da essência do ideal de justiça.

Além da ordem normativa nacional, a Organização Internacional do Trabalho (OIT)4 também traz importantes vetores sobre trabalho e dignidade, definidos no conceito de trabalho decente: geração de mais e melhores empregos com igualdade de oportunidades e de tratamento; erradicação do trabalho escravo e eliminação do trabalho infantil; e o fortalecimento dos atores tripartites e do diálogo social como um instrumento de governabilidade democrática (OIT, 2015).

Mostra-se, assim, oportuno estudar o trabalho da mulher policial, que tem sido uma constante na sociedade moderna. A Polícia Civil do Estado do Rio Grande do Sul é composta de cinco mil (5.000) servidores(as), cujo contingente de $40 \%$ são mulheres.

Consoante com Betiol (2000), a tomada de espaço pelas mulheres dá novos contornos e matizes às relações de trabalho. Cumpre destacar que o estudo da mulher policial encontra-se afeto ao campo da sustentabilidade, especificamente quanto a sua vertente social, relacionada à responsabilidade social corporativa. Justifica-se, portanto, analisar o ambiente corporativo na Polícia Civil do Estado do Rio Grande do Sul com relação ao trabalho decente para as mulheres policiais.

Desta forma, têm-se como objetivo geral deste estudo analisar o grau de aderência dos indicadores de trabalho decente propostos pela OIT (2008) no ambiente corporativo das mulheres na Polícia Civil do Estado do Rio Grande do Sul.

\section{REFRENCIAL TEÓRICO}

O referencial abordado traz os fundamentos de responsabilidade e sustentabilidade social em estreita ligação com o trabalho decente, voltados à mulher. $O$ estudo tomou por base os indicadores de trabalho decente estabelecidos pela OIT (2008), distribuídos em áreas temáticas.

\subsection{Trabalho decente}

A perspectiva do trabalho decente está atrelada aos conceitos de responsabilidade e sustentabilidade social, incluindo em seu escopo os principais indicadores voltados à melhoria das condições de trabalho, o que remete à qualidade de vida no ambiente laboral.

O vocábulo "decente" vai ao encontro de honesto e adequado, termos que, aliados a trabalho, levam à ideia de compatibilidade da atividade laboral com um piso mínimo de condição para qualidade de vida no trabalho.

4A OIT foi criada em 1919, como parte do Tratado de Versalhes, que pôs fim à Primeira Guerra Mundial. Fundou-se sobre a convicção primordial de que a paz universal e permanente somente pode estar baseada na justiça social. 
Dessa forma, a OIT atenta a sua missão histórica, e a partir da Declaração sobre os princípios e direitos fundamentais no trabalho, fruto da 86a Reunião da Conferência Internacional do Trabalho, realizada em Genebra no ano de 1998, cunhou o conceito de trabalho decente na 87a Reunião da Conferência, realizada no ano seguinte, na mesma cidade suíça.

Ghai (2003) observa que a noção de trabalho decente constou do Memorial do Diretor Geral da OIT, ao fim da 87a Reunião, e concentra, sob quatro elementos, diversas questões relacionadas a trabalho: proteção social, emprego, direitos do trabalhador e diálogo social.

A expressão trabalho decente veio ao mundo globalizado pela OIT, numa perspectiva de partilhar as características e problemas da vida no trabalho, de forma a reavivar e fomentar debates sobre a temática relacionada ao trabalho e ao trabalhador (BARZOTTO, 2007).

Nesse passo, o tema ganhou destaque na instância internacional, figurando como prioritário no Fórum Econômico Mundial e Fórum Social em 2000, na Cúpula do Milênio das Nações Unidas (projetado como um dos ODM - Objetivo de Desenvolvimento do Milênio), na Cúpula Mundial das Nações Unidas de 2005 e na Declaração do Conselho Econômico e Social da ONU de 2006. A seguir, em 2008, a própria OIT reafirmou a importância da política do trabalho decente com a "Declaração da OIT sobre a justiça social para uma globalização equitativa".

Verifica-se então que a concepção de trabalho decente foi desenvolvida no plano internacional com base nos quatro objetivos estratégicos da OIT (2015), visando à promoção de oportunidades para que homens e mulheres tenham acesso a trabalho produtivo de qualidade, em condições de liberdade, equidade, segurança e dignidade humana.

Assim, o trabalho decente, visto pela ótica da OIT, revela importantes traços para sua caracterização, demandando adequação aos quatro pilares ou eixos estratégicos já referidos, que podem ser mais bem definidos da seguinte forma: (i) pelo respeito às normas internacionais de trabalho e aos direitos laborais; (ii) pela geração de mais e melhores empregos e salários; (iii) pela proteção social pela extensão da seguridade; e (iv) pelo fortalecimento do diálogo social tripartite, tudo com vista à erradicação da pobreza, mitigação das desigualdades sociais e à garantia da governabilidade democrática, objetivando o desenvolvimento sustentável.

Mostra-se também evidente a intenção da OIT no sentido de ver articulados e inter-relacionados seus objetivos e propósitos, a partir dos elementos integrantes do conceito de trabaIho decente. Isso pode ser constatado a partir do primeiro eixo, que trata do respeito aos direitos fundamentais do trabalho, vetor protetivo que repercute nos outros três eixos, por estar ligado à liberdade, remuneração adequada, igualdade, seguro e diálogo social, representação e também à própria noção de dignidade do trabalhador.

É necessário destacar que o Brasil é signatário de diversas Convenções da OIT que tratam de temas relacionados a Direitos Trabalhistas, as quais, embora internacionais, pelo nosso sistema constitucional são consideradas como um ordenamento jurídico a ser respeitado (MENDES; COELHO; BRANCO, 2010). Podem ser assim citadas:

- Convenção sobre o trabalho forçado, 1930 ( $\left.n^{\circ} 29\right)$ e a Recomendação sobre a imposição indireta do trabalho, 1930 ( $\left.\mathrm{n}^{\circ} 35\right)$;

- Convenção sobre a liberdade sindical e a proteção do direito de sindicalização, 1948 ( $\left.n^{\circ} 87\right) ;$

- Convenção sobre o direito de sindicalização e de negociação coletiva, 1949 ( $\left.n^{\circ} 98\right)$;

- Convenção sobre a abolição do trabalho forçado, 1957 ( $\left.n^{\circ} 105\right)$;

- Convenção sobre igualdade de remuneração, 1951 ( $\left.n^{\circ} 100\right)$ e a Recomendação sobre o mesmo tema, 1951 ( ${ }^{\circ}$ 90);

- Convenção sobre discriminação (emprego e ocupação), 1958 (n 111) e a Recomendação sobre o mesmo tema, 1958 ( $\left.\mathrm{n}^{\circ} 111\right)$;

- Convenção sobre a idade mínima, 1973 ( $n^{\circ}$ 138) e a Recomendação sobre o mesmo tema, 1973 ( $\left.n^{\circ} 146\right)$; 
- Convenção sobre a proteção à maternidade, 2000 (n 183) e a Recomendação sobre o mesmo tema, 2000 ( $\left.n^{\circ} 191\right)$.

O reconhecimento da igualdade veio consagrado na Declaração Universal de Direitos Humanos de 1948 como decorrência do enaltecimento da dignidade da pessoa humana, onde se encontra ancorada. A Declaração, ao referir que todos os seres humanos são iguais em dignidade e direitos, toma a igualdade como pressuposto para o reconhecimento da dignidade (PIOVESAN, 2004). Segundo Sarlet (2001, p. 89), decorre da igualdade o tratamento isonômico, não discriminatório ou arbitrário, rechaçando a escravidão, a discriminação racial, perseguições por motivo de religião, sexo, enfim, toda e qualquer ofensa ao princípio isonômico na sua dupla dimensão, formal e material.

Com relação ao segundo eixo, geração de mais e melhores empregos, deve-se destacar que o tema evoca, além da criação de postos de trabalho, a promoção de qualidade no ambiente laboral, além de jornada de trabalho e remuneração adequadas, tudo com vista ao exercício do trabalho digno por parte do indivíduo. É necessário ainda ressaltar que, a exemplo de todas as políticas relacionadas aos Direitos Humanos, as vetoriais do trabalho decente apresentam caráter de universalidade.

O terceiro eixo, focado na proteção social, encontra-se relacionado com a segurança no trabalho, preconizando garantias ao trabalhador em momentos de crises financeiras, problemas de saúde ou eventos que o impossibilitem de trabalhar. Essa vetorial apresenta estreita relação com os direitos fundamentais do trabalho (primeiro eixo), que garantem auxílios doença e acidente, seguro-desemprego, licenças maternidade e paternidade e previdência social (CLT).

No âmbito da proteção social, ainda podem ser apontados benefícios de caráter universal, como saúde pública, recolocação e orientação profissional, oferta de cursos para qualificação do trabalhador, além de outros programas e benefícios que atendam indivíduos e famílias em situação de vulnerabilidade.

No quarto eixo, encontra-se o diálogo social, vetor que impõe necessidade de representação e voz ao trabalhador, com vista à equidade na relação de trabalho. $O$ tema procura garantir um patamar de equilíbrio nos polos da relação, com vista à produtividade e boa convivência no ambiente laboral.

Dos quatro pilares acima referidos, pode-se extrair, assim, questões relacionadas à remuneração, estabilidade, direitos e ao tipo de atividade que o trabalhador está realizando, ponto em que ganha importância a avaliação sobre riscos à saúde do trabalhador, sejam psicológicos, físicos ou por quaisquer enfermidades.

Ampliando um pouco a perspectiva de proteção social decorrente dos objetivos estratégicos da OIT, pode-se trazer Moraes (2004, p. 193):

os direitos sociais são direitos fundamentais do homem, caracterizando-se como verdadeiras liberdades positivas, de observância obrigatória em um Estado Social de Direito, tendo por finalidade a melhoria das condições de vida aos hipossuficientes, visando à concretização da igualdade social, e consagrados como fundamentos do Estado democrático, pelo art. 1ํ, IV, da Constituição Federal.

Observando ainda os eixos fundamentais do trabalho decente verifica-se que estes têm características próprias, mas que não são estanques, estando intimamente relacionados e interligados. Destaca-se que os pilares fundamentais do conceito de trabalho decente demonstram-se umbilicalmente ligados ao próprio conceito de dignidade humana, da qual o trabalhador é sujeito. A dignidade, que segundo Piovesan (2000, p. 54): 
(...) está erigida como princípio matriz da Constituição, imprimindo-lhe unidade de sentido, condicionando a interpretação das suas normas e revelando-se, ao lado dos Direitos e Garantias Fundamentais, como cânone constitucional que incorpora as exigências de justiça e dos valores éticos, conferindo suporte axiológico a todo o sistema jurídico brasileiro.

A dignidade afirma unidade aos direitos e garantias fundamentais, sendo inerente à pessoa humana, e consistindo em valor espiritual e moral que se manifesta singularmente na autodeterminação consciente e responsável da própria vida, induzindo respeito por parte das demais pessoas em um núcleo mínimo invulnerável de direitos fundamentais (MORAES, 1999).

Gosdal (2007) observa que no âmbito das relações de Direito Civil, desenvolvem-se cada vez mais propostas de "flexibilização" dos direitos dos trabalhadores, sob o argumento de que a empresa ocupa o centro das preocupações relativas ao trabalho, sendo necessário atentar para a dignidade da pessoa humana no âmbito das relações trabalhistas, e não só para o trabalho subordinado. Com a iniciativa da OIT, tem-se, assim, o início da construção de uma agenda de reconhecimento global relacionada à dignidade, à medida que traz o balizamento dos fatores para um piso mínimo de qualidade de vida para o trabalhador, seja ele autônomo ou assalariado. A OIT, dessa forma, impulsiona a criação de uma rede de proteção social, pretendendo abranger não somente a relação de emprego formal, mas também aqueles trabalhadores que não estão vinculados diretamente a uma relação de emprego clássica (BARZOTTO, 2007).

Neste ponto, cabe destacar que sustentabilidade é tema atual que não pode ser deixado ao largo de qualquer atividade humana, desde a consciência sobre a finitude dos recursos naturais. Paralelamente, a sociedade moderna está voltada à competitividade, mas cada vez mais, atenta para estratégias voltadas à inovação e inseridas no conceito de desenvolvimento sustentável em suas três vertentes: ambiental, econômica e social (ELKINGTON, 2012).

A dimensão social da sustentabilidade, do ponto de vista organizacional, ancora-se na responsabilidade social, a qual precisa abraçar duas grandes dimensões: a interna e a externa. A interna ganha sustentação nas estratégias e práticas direcionadas aos colaboradores, levados em conta os níveis de interferência nas suas condições de trabalho e a progressão na carreira. Nesse contexto, o agir da organização sobre a capacidade de atração e retenção de talentos passa pela gestão estratégica de carreiras, a qual apresenta aspectos peculiares. Para Bianchi e Quishida (2009, p. 89), "diferentemente do aspecto individual, as organizações não têm um processo contínuo de atividades a realizar na gestão de carreira, mas possuem uma série de estratégias a tomar que, se executadas de forma indepedente, possibilitam a gestão estratégica de carreira".

Nessa perspectiva, a produtividade passa então a ser buscada de forma articulada com a qualidade de vida no trabalho, que reflete positiva ou negativamente na motivação, satisfação pessoal e compromisso do trabalhador.

\subsection{A sustentabilidade social e o trabalho}

A sustentabilidade é um tema que tem se mostrado relevante e atual já há algumas décadas, de forma a influenciar comportamentos individuais e coletivos. Labuschagne e Brent (2005) apontam esse panorama, que tem levado as organizações a incorporar políticas e atividades ligadas à sustentabilidade para atender as múltiplas pressões sociais.

O desenvolvimento sustentável passou a ganhar relevo a partir de 1983, com a instituição da Comissão Mundial sobre o Meio Ambiente e Desenvolvimento no âmbito da ONU, seguida da publicação do relatório Nosso Futuro Comum em 1987. O documento é considerado um marco na discussão do desenvolvimento sustentável e é também conhecido como Relatório 
Bruntlan, em referência à presidente da comissão, Senhora Gro Bruntland, primeira Ministra da Noruega na época (JUNQUEIRA; MAIOR; PINHEIRO, 2011).

No relatório Bruntland é desenhada uma noção de desenvolvimento sustentável, a partir da formatação de um conceito bastante difundido e aceitado, dentre as dezenas de definições encontradas na doutrina em intenso debate sobre a temática da sustentabilidade, que abarca em verdade questões sociais, ambientais e econômicas. $O$ relatório conceitua desenvolvimento sustentável como aquele que atende às necessidades do presente sem comprometer a possibilidade das gerações futuras de atenderem às suas próprias necessidades.

A sustentabilidade passou a ganhar contornos ainda mais relevantes e definidos com o trabalho de John Elkington que, a partir do relatório Bruntland e das discussões e conceitos sobre o tema, cunhou um modelo denominado Triple Bottom Line (TBL, 1998), o qual acabou ganhando repercussão e amplo reconhecimento mundial. O modelo de Elkington (2001) considera e articula três distintas dimensões para o atendimento da sustentabilidade. Por essa perspectiva, o desempenho em termos de sustentabilidade só será adequado se houver atenção a três aspectos: o social, o ambiental e o econômico.

Elkington (2001) esclarece que a articulação dos vetores acima referidos implica em circunstâncias favoráveis à sustentabilidade como um todo. $\mathrm{O}$ mesmo autor ainda exemplifica com a interação entre os pilares econômico e social, o que gera ecoeficiência; com a interação entre as dimensões social e ambiental, o que leva à justiça social; e com a intersecção entre os vetores econômico e social, o que redunda em atendimento de ética organizacional, repercutindo interna e externamente à organização.

O conceito de sustentabilidade apresentado por Elkington (2012, p. 21) vem revelado como o "princípio de assegurar que nossas ações hoje não limitarão a gama de opções econômicas, sociais e ambientais disponíveis para as gerações futuras".

A dimensão social da sustentabilidade, deverá ser vista de forma articulada com os demais vetores da sustentabilidade, contando com indicadores próprios de sua dimensão, como os propostos por Labuschagne, Brent e Erck (2004) e Labuschagne e Brent (2005), que criaram um microssistema destinado à aferição da sustentabilidade pelo prisma social, levando em conta os stakeholders internos e externos; partes diretamente interessadas; e o desempenho macrossocial da organização.

Os estudos de Labuschagne, Brent e Erck, (2004) levam em conta indicadores constantes das Diretrizes para Elaboração dos Relatórios de Sustentabilidade (GLOBAL REPORTING INITIATIVE, 2002); Indicadores de Sustentabilidade do Instituto Wuppertal (1998); Comissão das Nações Unidas sobre Desenvolvimento Sustentável (CSD, 2001); e Métricas de Sustentabilidade do Instituto dos Engenheiros Químicos (ICHEME, 2002); perfazendo um conjunto bastante completo de indicadores.

Dessa forma, a prática social responsável, como nuance da sustentabilidade social, impõe uma gestão estratégica por parte de governos, organizações e empregadores em geral, voltada ao desenvolvimento humano dos colaboradores, de forma que a produtividade passe a ser perseguida de maneira articulada com a qualidade de vida no trabalho, que reflete positiva ou negativamente na motivação, na satisfação pessoal e no compromisso do trabalhador.

\subsection{Indicadores de trabalho decente}

Em continuidade ao que foi construído na 86a e 87ạ reuniões, em 2008 foi realizada pela OIT a 97a Conferência Internacional do Trabalho, na qual firmou-se uma Declaração sobre Justiça Social para uma Globalização Equitativa, com recomendação à adoção de estatísticas ou indicadores com a finalidade de avaliar e monitorar a evolução do trabalho decente pelos Estados-Membros. 
A Declaração foi adotada pela OIT e outros entes governamentais e não governamentais, ligados a trabalhadores e empregadores. Nesse contexto, foi criado pela OIT (2008) um compilado de indicadores distribuídos em dez áreas temáticas a saber:

a. Oportunidades de emprego;

b. Rendimentos adequados e trabalho produtivo;

c. Jornada de Trabalho Decente;

d. Conciliação entre o trabalho, vida pessoal e familiar;

e. Trabalho a ser abolido;

f. Estabilidade e segurança no trabalho;

g. Igualdade de oportunidades e de tratamento no emprego;

h. Ambiente de trabalho seguro;

i. Seguridade social;

j. Diálogo social e representação de trabalhadores e empregadores.

O trabalho decente é definido pela Organização Internacional do Trabalho (OIT), como um trabalho adequadamente remunerado, exercido em condições de liberdade, equidade e segurança, sendo assim capaz de garantir uma vida digna. Conforme Merino (2011), o Trabalho Decente não é intermediado em qualquer circunstância, nem terceirizado, a fim de que não haja precarização das condições de labor, evitando a superexploração do empregado.

Além da própria OIT, os indicadores relacionados ao trabalho decente são apresentados em diversos instrumentos que procuram desenvolver a responsabilidade social nas empresas. Dentre eles destacam-se: a Global Reporting Iniciative (GRI); os Indicadores Ethos de Responsabilidade Social e as normas SA 8000 e ISO 26000.

A Global Reporting Iniciative (GRI) é uma ampla rede independente composta por miIhares de indivíduos e organizações distribuídos em mais de 30 países e com sede em Amsterdã Holanda, constituindo-se também em um núcleo oficial de colaboração do Programa das Nações Unidas para o Meio Ambiente.

Na Categoria Social está inserida a subcategoria: Práticas Trabalhistas e Trabalho Decente, a qual envolve os seguintes aspectos: (i) Emprego; (ii) Relações Trabalhistas; (iii) Saúde e Segurança no Trabalho; (iv) Treinamento e Educação; (v) Diversidade e Igualdade de Oportunidades; (vi) Igualdade de Remuneração entre Mulheres e Homens; e (vii) Mecanismos de Queixas e Reclamações Relacionadas a Práticas Trabalhistas.

Além do GRI, existe no Brasil o Instituto Ethos de Empresas e Responsabilidade Social, organização sem fins lucrativos, caracterizada como Organização da Sociedade Civil de Interesse Público (OSCIP), cuja missão é "mobilizar, sensibilizar e ajudar as empresas a gerir seus negócios de forma socialmente responsável, tornando-as parceiras na construção de uma sociedade sustentável e justa" (INSTITUTO ETHOS, 2012). O seu objetivo principal é o estabelecimento de padrões de relacionamento das empresas com seus acionistas (shareholders) e stakeholders, visando a obtenção da confiança recíproca entre as partes, considerando este o valor básico e fundamental dessas relações, na esperança de que tais ações possam também influenciar os fornecedores e parceiros na disseminação de condutas socialmente responsáveis.

Na concepção do Instituto Ethos (2007) a Responsabilidade Social Empresarial (RSE) requer práticas de diálogo e engajamento entre a empresa e seus stakeholders na promoção da ética e da transparência. 
Em relação ao Público Interno, o Instituto Ethos declara que a Responsabilidade Social de uma empresa começa pelos investimentos no bem estar de seus colaboradores e dependentes, promovendo, assim, um saudável ambiente de trabalho. Em decorrência disso, impactando no alto grau das comunicações, na credibilidade dos acionistas quanto ao retorno esperado, e no fortalecimento de parcerias, resultando dessa maneira, na satisfação dos clientes (MELO NETO; FROES, 1999).

Pena (2003) acrescenta que a continuidade da RSE está pautada nos exemplos internos desenvolvidos e praticados pela gestão, estendidos à comunidade por meio de diálogo, respeito ao indivíduo e trabalho decente. No processo de implementação da ser, é importante a prática de gestão participativa, tanto com o público interno quanto com as entidades de classe, em decorrência da qual os resultados poderão representar maiores produtividade, motivação e comprometimento (SROUR, 2000).

Outro compromisso empresarial, está relacionado com a não discriminação e promoção da equidade racial, "não basta dizer não à discriminação, é preciso dizer sim à diversidade, esse horizonte positivo tem força de mobilização muito maior, porque nos leva mais longe e muito mais rápido" (INSTITUTO ETHOS, 2006, p. 86). Aceitar a diversidade requer o desenvolvimento de ações estratégicas nas organizações que vão desde a realização de campanhas de sensibilização sobre a diversidade até a abertura de fóruns de diálogos.

Não menos importante e relacionado ao público interno, está o compromisso com a promoção da equidade de gênero. A UNIFEM (2013)5 destaca a parceria entre a ONU Mulheres (Entidade das Nações Unidas para Igualdade de Gênero e o Empoderamento das Mulheres) e o Pacto Global das Nações Unidas através dos "Princípios de Empoderamento das Mulheres Igualdade Significa Negócios" que "oferecem à comunidade empresarial uma nova ferramenta no trabalho para ampliar e valorizar a liderança feminina no mercado de trabalho", podendo as empresas promover a igualdade de oportunidade entre os sexos.

$\mathrm{O}$ documento traz sete Princípios de Empoderamento das Mulheres a serem adotados pelas empresas que desejam sustentar esta equidade: (i) estabelecer liderança corporativa sensível à igualdade de gênero no mais alto nível; (ii) tratar todas as mulheres e homens de forma justa no trabalho, respeitando e apoiando os direitos humanos e a não discriminação; (iii) garantir a saúde, segurança e bem-estar de todas as mulheres e homens que trabalham na empresa; (iv) promover educação, capacitação e desenvolvimento profissional para as mulheres; (v) apoiar empreendedorismo de mulheres e promover políticas de empoderamento das mulheres através das cadeias de suprimentos e marketing; (vi) promover a igualdade de gênero através de iniciativas voltadas à comunidade e ao ativismo social; e (vii) medir, documentar e publicar os progressos da empresa na promoção da igualdade de gênero.

Destaca-se nesse contexto também a Social Accountability 8000 (SA8000), como uma norma internacional de avaliação da Responsabilidade Social que existe para empresas fornecedoras e vendedoras, cujo principal objetivo é garantir os direitos dos trabalhadores.

Na tentativa de promover a ação social das organizações, partindo de seu contexto interno, a Norma SA 8000 foi concebida com a finalidade de desenvolver a consciência social da organização, garantindo a segurança e a integridade do trabalhador. De acordo com BSD Brasil (2012), a norma SA 8000 foi lançada em outubro de 1997 pela Council Priorities Accreditation Agency (CEPAA), atualmente denominada Social Accountability International (SAI), organização não governamental norte-americana, e é composta por nove requisitos que tomam por base as Convenções da Organização Internacional do Trabalho, a Declaração Universal dos Direitos Humanos e a Convenção das Nações Unidas sobre os Direitos da Criança. Os requisitos da res-

5 Fundo de Desenvolvimento das Nações Unidas para Mulheres: estabelecido em dezembro de 1976 [1] originalmente como o Fundo Voluntário para a Década das Nações Unidas para Mulheres no Ano Internacional da Mulher. Fornece assistência financeira e técnica a programas e estratégias inovadores que promovem os direitos humanos das mulheres, a participação política e a segurança econômica. 
ponsabilidade social, de acordo com a SAI incluem: trabalho infantil; trabalho forçado; saúde e segurança; liberdade de associação e direito à negociação coletiva; discriminação; práticas disciplinares; horário de trabalho; remuneração e sistemas de gestão (SAI, 2012).

A ISO 26000 é uma norma internacional que fornece orientações sobre os princípios subjacentes à responsabilidade social, aos temas centrais e a questões pertinentes à responsabilidade social, além de fornecer orientações sobre formas de integrar o comportamento socialmente responsável com estratégias, sistemas, práticas e processos organizacionais existentes. Segundo a ISO 26000 , os princípios norteadores da responsabilidade social os quais apresentam-se pertinentes são: (1) accountability (responsabilidade); (2) transparência; (3) comportamento ético; (4) respeito pelo interesse das partes interessadas; (5) respeito pelo estado de direito; (6) respeito pelas normas internacionais de comportamento; e (7) respeito pelos direitos humanos (ABNT, 2012).

Essa Norma Internacional salienta a importância de resultados e melhorias no seu desempenho em responsabilidade social e dentro do tema central: Práticas Trabalhistas. Apresenta as seguintes questões, estritamente ligadas ao conceito de trabalho decente, conforme já destacado anteriormente: (i) emprego e relações de trabalho; (ii) condições de trabalho e proteção social; (iii) diálogo social; (iv) saúde e segurança no trabalho; e (v) desenvolvimento humano e treinamento no local de trabalho.

A denominação Qualidade de Vida no Trabalho (QVT) tem origem em Louis Davis, termo que surgiu em estudos relacionados a projetos sobre cargos, nos anos de 1970, atendendo a um só tempo aos anseios do trabalhador - relacionados ao seu bem estar e satisfação - e ao interesse da organização, que busca maior produtividade e eficácia a partir da qualidade de vida do empregado no ambiente laboral.

A temática da QVT apresenta grande relevância e ganha destaque nas décadas seguintes, quando passou a ser estudada por sua influência no processo produtivo, a partir do aumento da responsabilidade social da empresa com reflexos diretos no trabalhador e no trabalho (MARQUES; BORGES; ADORNO, 2008).

Nessa linha, o equilíbrio entre trabalho e espaço total de vida do trabalhador desponta nos estudos de Walton (1973), que destaca oito vetores inter-relacionados que influenciam a QVT conforme o quadro 2:

Quadro 2 - Vetores que influenciam a QVT

\begin{tabular}{l} 
compensação adequada e justa: equidade da remuneração com relação ao trabalho desenvolvido pelo \\
trabalhador; \\
\hline $\begin{array}{l}\text { segurança e saúde: tipo de trabalho desenvolvido, horários e jornada de trabalho, aspectos que podem } \\
\text { ser prejudiciais ao trabalhador; }\end{array}$ \\
\hline $\begin{array}{l}\text { oportunidade de uso e desenvolvimento das capacidades humanas: conhecimentos, informações sobre } \\
\text { o processo de trabalho, planejamento, habilidades, autonomia, tarefas completas; }\end{array}$ \\
\hline $\begin{array}{l}\text { garantia de trabalho e oportunidade de crescimento profissional: desenvolvimento pessoal e profissional, } \\
\text { estabilidade no emprego e progressão na carreira; }\end{array}$ \\
\hline $\begin{array}{l}\text { integração social na organização: desníveis hierárquicos, preconceitos, mobilidade e acesso aos cargos } \\
\text { mais elevados, colaboração e espírito de comunidade, relacionamento interpessoal; }\end{array}$ \\
\hline $\begin{array}{l}\text { constitucionalismo: princípios e regras organizacionais, direitos e deveres, privacidade, liberdade de ex- } \\
\text { pressão, igualdade, equidade, justiça no trabalho; }\end{array}$ \\
\hline $\begin{array}{l}\text { equilíbrio entre trabalho e espaço total da vida: conciliação entre o espaço familiar e de lazer do trabalha- } \\
\text { dor com os compromissos de trabalho; }\end{array}$ \\
\hline $\begin{array}{l}\text { relevância social do trabalho: imagem da empresa e sua responsabilidade social e sua influência na au- } \\
\text { toestima do trabalhador. }\end{array}$ \\
Fonte: Elaborado com base em Walton (1973).
\end{tabular}

Fonte: Elaborado com base em Walton (1973). 
Para Limongi-França e Rodrigues (2012), há ligação direta entre a origem do conceito de QVT e as condições humanas e de ética do trabalho, que englobam não só questões relativas aos riscos à segurança e saúde, mas também temas relacionados ao próprio significado do trabalho, consideradas assim suas implicações éticas, ideológicas e a equidade na contraprestação pelo esforço do trabalhador.

\subsection{Trabalho da mulher}

Falar em trabalho da mulher é falar em perspectiva de gênero, e o termo gênero deriva de um conceito socialmente concebido, que alude à distinção entre os sexos, mas também tem relação com estruturas, instituições, ritos e práticas constitutivas das relações sociais cotidianas entre homens e mulheres (GROSSI, 1998).

O princípio da igualdade pressupõe que as pessoas colocadas em situações diferentes sejam tratadas de forma desigual: "Dar tratamento isonômico às partes significa tratar igualmente os iguais e desigualmente os desiguais, na exata medida de suas desigualdades" (NERY JUNIOR, 1999, p. 42).

Desde a antiguidade a perspectiva de gênero discrimina e determina a divisão do trabaIho. Atividades como a pesca e a caça eram atribuídas aos homens, que detinham maior força física; a coleta de frutos e o cultivo da terra destinavam-se às mulheres, por serem consideradas tarefas mais frágeis e delicadas. Passaram-se milhares de anos e verifica-se que o panorama laborativo contemporâneo é ainda fortemente marcado pela questão de gênero. Engels $(1985$, p. 178) afirma que:

O homem vai à guerra, incumbe-se de caça e da pesca, procura a matéria-prima para a alimentação, produz os instrumentos necessários. A mulher cuida da casa, prepara a comida e confecciona as roupas: cozinha, fia e cose. Cada um manda no seu domínio: o homem na floresta, a mulher em casa. Cada um é proprietário dos instrumentos que elabora e usa: o homem possui as armas e os apetrechos de caça e pesca, a mulher é dona dos utensílios caseiros.

A Constituição Federal de 1988 faz referência expressa à igualdade em diversos dispositivos, destacando-se o Artigo 5으, caput, e o Artigo 5으, I que preveem, respectivamente, que todos são iguais perante a lei e, especificamente, a igualdade em direitos e obrigações.

Pamplona (2000) observa que a introdução das mulheres no mercado de trabalho deu-se mais pela sua condição como mão de obra dócil e barata do que pelo reconhecimento da igualdade. Segundo o mesmo autor, isso remeteria à conclusão de que os reflexos do capital estão por trás das grandes transformações sociais e jurídicas, refletindo inclusive no surgimento do Direito do Trabalho.

A visão baseada numa suposta inferioridade do gênero feminino, segundo Alves (1997), tem sustentação na cultura marcadamente patriarcal, que exerce influência desde a educação familiar, passando pela escola, pela mídia de massa e pelas religiões. Esta suposta inferioridade levou à elaboração de uma legislação impregnada de forte carga discriminatória, que se constitui muitas vezes em obstáculo para que as mulheres tomem posições de comando e decisão em organizações e na sociedade.

Bandeira e Melo (2010) afirmam que, a despeito de todas as barreiras e dificuldades, a literatura identifica a presença de mulheres em momentos importantes da história do Brasil, desde 1822. A partir de então, muitos avanços ocorreram com relação ao trabalho feminino, mas, em pleno século XXI, as mulheres continuam sendo discriminadas e sub-representadas no campo laborativo além das fronteiras domésticas, denotando a vigência de um modelo ainda baseado em perspectiva ideológico-cultural de exclusão e dominação.

Para Bruschini (2000), a participação da mulher no mercado de trabalho brasileiro apresentou significativo crescimento, principalmente a partir da década de 1990. Todavia, a par de todas as conquistas, as relações de gênero ainda são marcadas por muitas assimetrias. Nascimento (1996) observa que 
as diferenças entre mulheres e homens são construídas socialmente e, por isso, passíveis de mudanças.

De forma velada, as posições de maior destaque e os maiores salários nas organizações ainda pertencem ao gênero masculino (CÁLAS; SMIRCICH, 1999). A quebra de barreiras culturais vem ocorrendo ao longo dos anos, com a consequente ascensão da mulher sob perspectiva individual e profissional. Atualmente temos o sexo feminino em relevante parcela de funções, inclusive na área de segurança pública, situação impensável há algumas décadas (CARVALHO NETO; TANURE; ANDRADE, 2010).

Bulos (2002) fala em igualdade proporcional, quando nega o tratamento igual para situações oriundas de situações fáticas desiguais. Para esse autor "o raciocínio que orienta a compreensão do princípio da isonomia tem sentido objetivo: aquinhoar igualmente os iguais e desigualmente as situações desiguais" (BULOS, 2002, p. 52). Verifica-se, portanto, a ordem constitucional permite e até fomenta a distinção de tratamento, a partir de juízos de valor que determinem o tratamento desigual aos sexos, exatamente para garantir a igualdade quando verificada a existência de uma finalidade razoavelmente proporcional ao fim visado (MORAES, 1999).

No que tange às distinções entre feminino e o masculino, e sob perspectiva da igualdade material, destacam-se alguns dispositivos constitucionais que visam assegurar a igualdade de direitos e obrigações com a previsão de tratamento diferenciado, a saber: Artigo 70 XVIII que dispõe sobre a licença à gestante em período superior à licença-paternidade; Artigo 40, parágrafo 10 , III, a e b , bem como o artigo 201, parágrafo 70, da Constituição Federal, que dão tratamento diferenciando à mulher, diminuindo o tempo necessário para se aposentar. Não obstante, os dispositivos acima referidos, o artigo 7ํ, XXX, da CF proíbe a diferença de salários, de exercício de funções e de critério de admissão por motivo de sexo, idade, cor ou estado civil.

Partindo do raciocínio acima, dar tratamento igualitário a mulheres e homens, pressupõe considerar as diferenças, desnivelando-os, sob pena de estar-se cometendo discriminação pelo uso da própria igualdade, quando despida de sua dimensão substancial.

Canotilho (1998) faz coro, referindo que a violação do princípio da igualdade só ocorre quando indivíduos em situações iguais não são arbitrariamente tratados como desiguais. Para esse doutrinador, trata-se da proibição do arbítrio; a distinção rechaçada é aquela que deriva de uma discriminação irrazoável, desproporcional, arbitrária.

Betiol (2000) refere que o mercado de trabalho mundial, ao longo da história, vem sendo impactado por transformações demográficas, sociais, culturais e jurídicas, cujas transições induziram diversas pesquisas e estudos baseados na perspectiva de gênero e focados no movimento pela conquista de direitos pelas mulheres (SCOTT, 1995; MILL, 2006; BEAUVOIR, 2009; BANDEIRA e MELO, 2010; TOURAINE, 2011).

\section{MÉTODO}

Como método de pesquisa, optou-se por uma abordagem qualitativa, destacada por Beuren (2004) por permitir análises mais aprofundadas em relação ao objeto de pesquisa e estudo, sendo, portanto, uma forma bastante adequada para se conhecer a natureza de um fenômeno social. A coleta dos dados se deu por meio de entrevistas semi-estruturadas, de forma a instigar o entrevistado a seguir espontaneamente a linha de seu pensamento e de suas experiências, dentro do foco principal colocado pelo investigador, sem identificação dos entrevistados (TRIVIÑOS, 2007). Por se tratar de uma pesquisa qualitativa, a interpretação dos dados foi realizada utilizando-se o procedimento de análise de conteúdo (BARDIN, 2009).

Na sequência serão apresentadas as fontes de evidência, unidades de análise e os procedimentos de análise dos dados. 


\subsection{Fontes de evidência e unidades de análise}

A coleta de dados foi realizada a partir de diversas fontes de evidências, fazendo-se uso de dados primários e secundários. Os dados primários foram coletados por meio de entrevistas com delegadas e servidoras policiais do Estado do Rio Grande do Sul e os dados secundários a partir de documentos, relatórios de pesquisas e registros da Polícia Civil do Estado, o que encontra amparo científico em Denzin (1989).

Para a realização das entrevistas foi elaborado um roteiro para observação (Anexo 01) e um instrumento flexível composto com perguntas abertas (Anexo 2), que possibilitaram ao entrevistado discorrer sobre pontos relacionados à temática central do estudo (SANTOS, 2005). $O$ roteiro foi baseado nas notas referenciais e também na realidade vivida pelas servidoras entrevistadas. Para tanto, foram realizadas dez entrevistas. Destaca-se que foi realizado pré-teste com três profissionais com perfil adequado para pesquisa, os quais depois foram complementados e integram o resultado final ao lado dos demais achados da pesquisa.

A entrevista semiestruturada é:

[...] aquela que faz parte de certos questionamentos básicos, apoiados em teorias e hipóteses, que interessam à pesquisa, e que, em seguida, oferecem amplo campo de interrogativas, fruto de novas hipóteses que vão surgindo à medida que se recebem as respostas do informante. Dessa maneira, o informante, seguindo espontaneamente a linha de seu pensamento e de suas experiências dentro do foco principal colocado pelo investigador, começa a participar na elaboração do conteúdo da pesquisa (TRIVIÑOS, 2007, p. 146).

Para manter o sigilo, sem prejudicar a veracidade da pesquisa, foram codificadas as entrevistadas que serviram como unidades de análise, passando a serem denominadas, as delegadas, sob os códigos DELTA1, DELTA2 e DELTA3; e agentes policiais - as escrivãs e inspetoras - sob os códigos ALFA1, ALFA2, ALFA3, ALFA4, ALFA5, ALFA6, ALFA7. Destaca-se que foi utilizado o mesmo instrumento para ambas, embora tenham sido captadas realidades diversas em razão de que são funções distintas.

A escolha dos sujeitos da pesquisa teve como objetivo proporcionar a maior abrangência possível do estudo. Assim, observado o critério de acessibilidade, foram eleitas unidades de análise em diferentes regiões e cidades, com cargos, funções e tempos de serviço distintos.

Ainda, levou-se em conta a característica do destaque profissional de agentes e delegadas, em cidades, funções e regiões distintas, que teve como por objetivo pluralizar o ambiente de coleta da pesquisa, para captar diferentes realidades frente às peculiaridades locais de cada região do Estado do RS.

Foram entrevistadas servidoras que desempenham funções diversas na estrutura dos órgãos policiais, visando colher percepções de realidades distintas no ambiente organizacional. As entrevistas foram gravadas, mediante autorização das entrevistadas, possibilitando levantar o maior número de evidências.

Tanto as entrevistas quanto as observações, foram aplicadas pelo pesquisador no período de primeiro de dezembro de 2015 a dez de fevereiro de 2016. Todas as entrevistas foram transcritas e codificadas, realizando uma análise de conteúdo das principais evidências expostas, tendo como base as categorias de análise que formam o conceito de trabalho decente da OIT.

As observações aconteceram in loco, a partir das visitas às unidades policiais e entrevistas com as servidoras, o que segundo Triviños (2007, p. 154) "satisfaz as necessidades principais da pesquisa qualitativa, por exemplo, a relevância do sujeito, da prática manifesta do mesmo e ausências total ou parcial, de estabelecimento de pré-categorias para compreender o fenômeno que se observa". 
O pesquisador buscou estar atento às características regionais e municipais onde se situava o órgão de lotação das entrevistadas, a começar pela situação socioeconômica e pelos números relativos à criminalidade local. As principais evidências das observações estão relacionadas à estrutura de trabalho e recursos humanos, que seguem condições prediais, limpeza, equipamentos, viaturas, armamento, número de policiais lotados na delegacia, estrutura de comando e outros aspectos.

\subsection{Procedimentos de análise dos dados}

Por se tratar de uma pesquisa qualitativa, a interpretação dos dados foi realizada utilizando-se o procedimento de análise de conteúdo (BARDIN, 2009).

A análise foi desenvolvida por um processo de sistematização progressivo e analógico, com abordagem indutivo-construtiva (MORAES, 1999) levando à categorização dos dados. Seguindo Vergara (2005), as categorias foram rearranjadas durante o andamento do estudo.

As etapas de análise de conteúdo, conforme Dellagnelo e Silva (2005), são organizadas em: (i) pré-análise; (ii) exploração e análise do material; (iii) interpretação.

Para este foram seguidas as etapas sugeridas por Moraes (1999):

$\diamond$ Preparação das informações (seleção e codificação);

৩ Unitarização ou transformação do conteúdo em unidades de análise;

$\checkmark$ Categorização ou classificação das unidades em categorias;

$\diamond$ Descrição.

A seguir, apresenta-se os resultados da pesquisa e análises.

\section{RESULTADOS E DISCUSSÕES}

Os resultados a seguir apresentados estão organizados conforme as áreas temáticas dos indicadores de trabalho decente propostos pela OIT, 2008.

\subsection{Oportunidades de emprego}

O critério oportunidades de emprego (e no emprego), foi referido por praticamente todas as entrevistadas, como sendo a principal circunstância que as levou à carreira policial, cabe destacar que todas prestaram concurso público, tendo participado, portanto, de seleção pública aberta, o que em tese indica atendimento a critérios de isonomia e não discriminação para a mulher quanto à oportunidade de emprego. Em alguns relatos, foram identificadas distinções nas condições entre o gênero masculino e feminino, como por exemplo: "P'ras mulheres era menor a corrida... do que p'ros homens... o tempo era menor... quer dizer... havia aquela coisa específica praquilo que a mulher podia fazer...", ainda especificamente quanto aos aspectos relacionados aos fatores de ingresso na Polícia Civil, verifica-se que a circunstância mais referida como determinante da escolha da carreira policial é a própria oportunidade do concurso, que surgiu atendendo à perspectiva de outros anseios das entrevistadas.

Além da oportunidade do concurso, foram destacadas motivações despertadas pelo incentivo e apoio de amigos e parentes, bem como a atração pelo dinamismo da carreira policial e do Direito Penal, complementados por relatos de experiências de profissionais do serviço ativo. Os primeiros obstáculos à mulher na polícia começam a ser retratados nos relatos que fazem alusão ao treinamento físico para o concurso, descrevendo circunstâncias que impõe maior dificuldade para as mulheres 
em geral, pela questão da maternidade, exclusiva do gênero feminino. Outro aspecto relatado diz respeito ao grande número de mulheres reprovadas em testes psicotécnicos e testes físicos. Destaca-se também que determinada servidora, com 31 anos de serviço policial, tendo desempenhado importantes funções na corporação, ainda não conseguiu galgar o último posto na carreira, o que pode estar relacionado à questão da oportunidade de progressão da mulher policial, porém, segundo a percepção ainda desta servidora, a mulher tem mais espaços do que na época do seu ingresso na polícia, inclusive porque se adaptou aos mecanismos da carreira policial: "Tem mais oportunidade... Elas se equilibram... é que na minha época foi muito duro... éramos muito poucas...", Percebe-se que as mulheres ainda têm menos chances no exercício da função, ficando limitadas pelo estereotipo feminino, mesmo tendo aptidões para realizarem funções que tem sido atribuídas aos homens. Cabe ressaltar que as oportunidade de cargos mais altos ainda são ofertadas a eles.

$\mathrm{O}$ aspecto da carência de oportunidades durante o exercício da função foi revelado por quase todas as entrevistadas, sob menção do aspecto cultural e do machismo. Outra circunstância relevante apontada, por exemplo, está relacionada ao prejuízo de oportunidades a partir do gozo da licença maternidade, o que revela situação de grande iniquidade para a mulher, que acaba sendo penalizada por uma situação natural que demanda o exercício de um direito legítimo da mulher trabalhadora. Quase todas as entrevistadas reconhecem a maior fragilidade do feminino, principalmente quando relacionado aos limites de prática de algumas atividades policiais que demandam força física. Houve, contudo, ressalva no sentido de que não se trata de inferioridade, mas sim de distinção por peculiaridade do gênero, não sendo obstáculo ao exercício da função policial.

Concluindo a apresentação e análise referente ao primeiro critério do trabalho decente da OIT, observou-se um déficit para a mulher policial em relação ao homem policial, tanto nas condições de ingresso na carreira e curso de formação, quanto nas oportunidades durante o exercício da atividade, com menos chances de progressão funcional e reflexos nos demais critérios do trabalho decente. Essas limitações podem implicar obstáculos à ascensão funcional e ao livre exercício do trabalho, desatendendo assim aos critérios de trabalho decente da OIT. Este aspecto é corroborado por Proni (2013) que também destacou uma maior incidência de situações vulneráveis entre as mulheres em comparação com os homens. Em termos absolutos, o número de mulheres economicamente ativas era bem menor que o de homens.

\subsection{Rendimentos adequados e trabalho produtivo}

Observa-se, da análise dos dados coletados, que as entrevistadas podem ser segmentadas em dois grupos quando se trata da percepção quanto aos seus rendimentos salariais. De um lado podem ser identificadas opiniões no sentido de que o salário está adequado e justo; de outro observa-se inconformidade com o salário, baseada no ambiente de risco e outras peculiaridades da função como a jornada de trabalho exaustiva e excessiva.

Numa outra perspectiva, segmentando as entrevistadas pela função, verificam-se também percepções distintas. As que percebem seu salário como adequado - agentes policiais, escrivãs e inspetoras - fazem expressa alusão aos trabalhadores de outras áreas, cujos rendimentos são inferiores aos seus. Já no tocante às entrevistadas delegadas, ocorre o inverso, comparam a atividade com outras carreiras jurídicas de Estado e observam que não há a devida valorização para a função policial, não obstante todas as agruras que a fazem muito mais extenuante.

Deve ser destacado que, com algumas falas dissonantes, no geral, as entrevistadas revelam conformidade com os ganhos, embora sob menção de que a função deveria ser mais bem remunerada e que não há a devida contraprestação por horas-extras trabalhadas e regimes de sobreaviso. No mesmo passo, a quase totalidade refere que houve sensível melhora na situação 
remuneratória, a partir de recentes conquistas em termos de salário e carreira, as quais estão sendo implementadas paulatinamente.

Com relação à valorização social pelo trabalho realizado, também se observa junto à quase todas as entrevistadas a sensação do reconhecimento por parte da comunidade. Despontam assim traços que revelam cultura machista, no sentido de que a atividade policial ainda é vista por alguns integrantes da comunidade como sendo inerente ao masculino. Tangenciando a questão remuneratória e o reconhecimento da comunidade, vale registrar que muitas das entrevistadas revelaram-se bastante gratificadas por exercer a função policial. Num aspecto mais relacionado à valorização interna, foi identificado desvelo da instituição em pelo menos duas das entrevistas, o que demonstra pouca reconhecimento interno ao servidor policial e ao trabalho realizado. Segundo essas percepções, a valorização e o reconhecimento maior viriam da comunidade e não das instâncias superiores na polícia.

Em análise final relativa ao indicador que trata dos rendimentos e trabalho produtivo, pode-se concluir que, embora haja espaço para evoluir, a questão está adequada aos padrões pretendidos pela OIT. Diversas entrevistadas referiram que houve avanços significativos com o governo em termos de salário e de escalonamento de carreira nos últimos anos, cuja implementação vem sendo progressiva, proporcionando melhora significativa ao longo do tempo.

Tem-se, assim, por parcialmente atendido o que preconiza a OIT quanto à remuneração adequada e justa ao trabalho da mulher policial. Respectivamente, são direitos fundamentais do trabalho e emprego de qualidade com remuneração adequada, visando à dignidade do trabalhador e numa perspectiva maior à erradicação da pobreza e mitigação das desigualdades, objetivando o desenvolvimento sustentável.

\subsection{Jornada de Trabalho Decente}

Da análise realizada sobre os dados coletados com relação à jornada de trabalho, deve-se destacar já de início que foi referida uma jornada de trabalho excessiva, desgastante e não devidamente remunerada. Essa percepção encontra-se de forma muito marcante em vários relatos sobre insuficiência na disponibilidade de horas-extras, compensação de horas de trabalho, serviços extraordinários, regimes de sobreaviso, regime de trabalho ininterrupto, entre outros. Essa situação de inadequação da jornada de trabalho é encontrada tanto nas delegacias do interior quanto nas de cidades maiores. Em alguns casos, por exemplo, as delegacias não têm serviço de plantão e se instala um regime de sobreaviso quase permanente. Esses exemplos explicitam jornadas de trabalho totalmente inadequadas ante a ótica da OIT, 2008. Além da exaustividade de ficar uma semana toda de sobreaviso, ainda não há remuneração nem compensação com dias de folga.

No indicador jornada de trabalho, verifica-se, portanto, inadequação aos parâmetros da OIT, sendo revelados os maiores problemas ao atendimento de critérios mínimos de dignidade quanto à atividade laborativa, com vários pontos destacados como negativos.

No âmbito deste indicador do trabalho decente, pode-se aludir Marques, Borges e Adorno (2008), que fazem referência à qualidade de vida no trabalho (QVT) como decorrência da responsabilidade social, a qual impõe o atendimento de um piso mínimo de condições para o trabalhador e implica diretamente o processo produtivo.

Em análise final quanto ao indicador jornada de trabalho, pode-se inferir que não atende aos critérios da OIT, notadamente quanto aos eixos que tratam dos direitos fundamentais do trabalho e do emprego de qualidade. Foi relevada uma jornada de trabalho excessiva e que, no mais das vezes, nem a devida contraprestação pecuniária. Quanto à analise sob perspectiva de gênero, verifica-se que a situação é ainda pior para a mulher, todavia, por motivos que estão afe- 
tos a outros indicadores do trabalho decente, como ambiente de trabalho, conciliação da dupla jornada e falta de mecanismos de igualdade material.

\subsection{Conciliação entre o trabalho, vida pessoal e familiar}

As entrevistadas destacaram com maior ênfase as circunstâncias como maternidade, dupla jornada e seus reflexos, além de ressaltada a maior carga de responsabilidade da mulher nas relações familiares. Também é destacada com frequência a necessidade de apoio do marido, da família e até de amigos, para atender às necessidades dos filhos. Isso ficou evidenciado em diversas falas. Algumas entrevistadas revelaram também a dificuldade de aceitação dos maridos quanto a peculiaridades da função, como deslocamentos e atendimentos fora do horário de expediente.

Quando perguntadas sobre a perspectiva de gênero, na percepção delas é mais fácil para o homem conciliar a profissão e a vida pessoal: "Sim, acredito que para os homens é mais fácil, mesmo quando se trata de filhos." Muitas são solteiras por isso já. Muitas separaram por isso... têm sérios problemas por isso... e muitas já falam que são solteiras por opção..." .

Encaminhando as conclusões sobre este indicador, pode-se destacar observações que demonstram um cenário geral de dificuldade para a mulher, tanto nas relações familiares como nas relações sociais, acrescentado a uma atividade policial que transforma as pessoas. Aranha (1996, p. 15) toca nessa questão, ao referir que "o trabalho modifica também a maneira de pensar, agir e sentir, de modo que nunca permanecemos os mesmos ao fim de uma atividade, qualquer que ela seja... o homem se autoproduz, ao mesmo tempo em que produz sua própria cultura".

A demanda de dedicação exclusiva e diuturna por parte dos servidores da polícia é grande. Essa dificuldade impacta mais na vida das mulheres casadas e das que têm filhos pequenos, do que com as demais, demonstrando o não atendimento desse importante vetorial do trabalho decente da OIT, 2008.

Neste indicador ficou evidenciado a clara inadequação aos critérios do trabalho decente da OIT, 2008. Isso se comprovou, notadamente, nos direitos fundamentais no trabalho e qualidade no emprego, por circunstâncias, que a exemplo do que fora referido nas análises anteriores, tem estreita ligação também com outros indicadores, como ambiente e jornada de trabalho e igualdade.

\subsection{Trabalho a ser abolido}

Na pesquisa observou-se que as duas questões mais apontadas pelas entrevistadas foram o regime de sobreaviso e a falta de efetivo, o que leva os policiais a trabalharem muitas vezes sozinhos na delegacia e em diligências externas. Essa situação foi ainda destacada por algumas entrevistadas sob expressa menção de insegurança e risco, contexto que seria ainda pior para a mulher, pela maior fragilidade física.

Consoante com o que já foi descrito em outros momentos da análise dos dados coletados nessa pesquisa, a questão do efetivo é um tema que foi observado como subjacente a diversos indicadores de trabalho decente pesquisados. Essa influência revelou prejuízo aos servidores policiais e mais à mulher em particular, devido à condição física de maior fragilidade.

Além dos problemas relacionados ao efetivo, as entrevistadas apresentam situações pertinentes à necessidade de adequações legislativas e práticas de gestão interna. Foram assim citados registros de ocorrências e instaurações de procedimentos policiais desnecessários. Também surgiu referência a má gestão de pessoal, com sobreposição de atividades e desperdício de recursos humanos em funções administrativas. 
Em conclusão sobre a análise do atendimento deste indicador, verifica-se que o critério: trabalho a ser abolido, revelou destaque a pontos comuns a outros indicadores, como por exemplo, segurança no ambiente de trabalho e jornada de trabalho decente, destacando nesse ponto a falta de efetivo necessário para as atividades policiais, que foi relatada com muita frequência e foi uma realidade constatada pela observação nas delegacias.

\subsection{Estabilidade e segurança no trabalho}

Os resultados e a respectiva análise dos dados referentes a este critério de trabalho decente revelam cenário de estabilidade e segurança, sendo estes circunstâncias primordiais na escolha de uma carreira pública iniciada por concurso, embora impactado por questões políticas atuais relacionadas a remuneração.

A análise deste indicador destaca a percepção geral de que há estabilidade para as mulheres policias em paridade com os homens e, portanto, atendimento a esse vetorial do trabalho decente.

\subsection{Igualdade de oportunidades e de tratamento no emprego}

Neste quesito, muitas foram as manifestações com referências ao atendimento de mecanismos de igualdade substancial na primeira fase do concurso público, com provas físicas diferenciadas para a mulher.

No geral, o conjunto das entrevistas revelou muitos pontos ligados à igualdade, podendo ser citados a discriminação, o respeito à mulher e a igualdade no ambiente de trabalho, todos bastante presentes durante a coleta de dados. Dentre as situações de discriminação que geraram desconformidade por parte das entrevistadas, a mais referida foi a não convocação - ou convocação de mulheres em menor número que homens - para operações policias e atividades de rua. O contexto encontrado a partir da coleta dos dados demonstra também que as funções de cartório, secretaria e funções administrativas são mais destinadas ao feminino nos órgãos policiais, enquanto as posições no setor de investigação são preenchidas pelos homens.

A maior fragilidade e falta de força física foi aludida por quase todas as entrevistadas, sendo no mesmo passo reconhecida como limitadora de algumas atividades. Todavia, na análise do pesquisador quanto ao contexto, a referência ao medo não revela covardia, mas sim o contrário, verifica-se que as servidoras dizem ter medo de não corresponder às expectativas nela depositadas como mulher policial.

Os achados acima destacados vão ao encontro de Betiol (2000), para quem a tomada de espaço pelas mulheres forma novos contornos e matizes às relações de trabalho, que ganham outros significados, à medida que o masculino e o feminino passam a dividir oportunidades, posições e cargos de destaque nas organizações e na sociedade.

Outro aspecto destacado está relacionado aos equipamentos pessoais e de defesa, projetados para uso masculino, mostrando inadequações ao corpo e estrutura feminina.

Concluindo a apresentação e análise do vetor igualdade, deve-se referir que foram encontrados indicativos que destoam do conceito de trabalho decente da OIT 2008, notadamente quanto ao primeiro eixo - direitos fundamentais - que revela a pretensão de eliminar toda forma de discriminação no trabalho, impondo, assim, a eliminação da discriminação em função de gênero ou outra circunstância qualquer. Os dados coletados junto às entrevistas revelam uma desconformidade com a situação de desigualdade vivenciada pelas mulheres na Polícia Civil, podendo concluir que a polícia precisa avançar muito em busca da igualdade material, com adequações que possibilitem à mulher exercer seu trabalho com liberdade, igualdade e dignidade, nas mesmas condições que os homens. 


\subsection{Ambiente de trabalho seguro}

Já de início pode ser inferir que situação predial foi classificada como inadequada por quase todas as entrevistadas, além de ser um dos maiores fatores de risco à atividade. Quando perguntadas sobre esse ambiente de risco frente à condição feminina, em geral, indicam que o ambiente é mais inseguro para a mulher, pela condição de maior fragilidade física, o que torna muito mais arriscado trabalhar e permanecer sozinha em uma delegacia de polícia, como costuma ocorrer em nosso Estado face à precariedade no número de recursos humano. Da mesma forma, o atendimento de ocorrências externas é apontado como inseguro.

Deve-se, ainda, destacar que algumas entrevistadas revelaram as mudanças que o ambiente policial provoca na personalidade: "muitas mulheres embruteceram... começavam a ter comportamentos igual aos homens... ", declarou uma das entrevistadas. Dos relatos coletados junto às entrevistadas, pode-se extrair conclusões no sentido de que o trabalho desenvolvido na Polícia Civil é inseguro para muito além dos riscos inerentes à própria atividade.

A pesquisa revelou precariedade, fragilidade e insegurança em prédios, viaturas, coletes e equipamentos. Também ficou evidenciada a situação da precariedade no contingente de recursos humanos que além da sobrecarga no trabalho, acarreta insegurança extrema aos policiais que trabalham sozinhos nas delegacias e em atividades externas.

\subsection{Seguridade social}

Quanto à seguridade foram observadas poucas referências nas falas das entrevistadas, tendo a maioria referido que a questão está adequada; algumas ainda observaram avanços recentes na questão da aposentadoria especial da mulher e possibilidade de promoções mesmo em período de licença-maternidade.Essa adaptação do critério de promoções, permitindo a concorrência da mulher em licença maternidade, demonstra a consolidação de direitos citadas por Alvesson e Billing (1997).

Os dados colhidos junto das entrevistadas revelaram atendimento desta vetorial do trabalho decente. Ressalte-se, todavia, que o indicador de seguridade está relacionado à proteção social, objeto do terceiro eixo temático do trabalho decente da OIT (2008), que busca segurança no trabalho e preconiza garantias ao trabalhador em momentos de crises financeiras, problemas de saúde ou eventos que o impossibilitem de trabalhar. Essa vetorial apresenta estreita relação com os direitos fundamentais do trabalho (primeiro eixo), que garantem auxílios doença e acidente, seguro-desemprego, licenças maternidade e paternidade e previdência social (CLT).

\subsection{Diálogo social e representação de trabalhadores e empregadores}

No quesito diálogo social, embora tenha havido uma referência a influências políticas e dificuldade nas relações entre polícia e governos, existe um diálogo social e uma representação sindical adequada. No mesmo sentido, observou-se que, no geral, as mulheres têm voz interna e externa com os colegas, chefias e sindicato.

Destaca-se, ainda, que o indicador encontra-se no âmbito do quarto eixo do trabalho decente da OIT, 2008, algo que preconiza o direito de representação e voz ao trabalhador, para garantir um patamar de equilíbrio nos polos da relação, em prol da produtividade e boa convivência no ambiente laboral, com vista à equidade na relação de trabalho.

O Quadro 3 apresenta a percepção da pesquisa quanto ao atendimento ou não do que preconiza a OIT 2008 para cada indicador de trabalho decente. 
Quadro 3: Grau de aderência à OIT 2008.

\begin{tabular}{|c|c|}
\hline INDICADOR DE TRABALHO DECENTE & ADERÊNCIA A OIT 2008 \\
\hline Oportunidades de emprego & Desatendimento \\
\hline Rendimentos adequados e trabalho produtivo & Atendimento Parcial \\
\hline Jornada de Trabalho Decente & Desatendimento \\
\hline Conciliação entre o trabalho, vida pessoal e familiar & Desatendimento \\
\hline Trabalho a ser abolido & Análise prejudicada \\
\hline Estabilidade e segurança no trabalho & Atendimento Total \\
\hline Igualdade de oportunidades e de tratamento no emprego & Desatendimento \\
\hline Ambiente de trabalho seguro & Desatendimento \\
\hline Seguridade social & Atendimento Total \\
\hline Diálogo social e representação de trabalhadores e empregadores & Atendimento Total \\
\hline
\end{tabular}
Fonte: Dados da pesquisa

Dos dez indicadores analisados, apenas 03 (três) foram classificados como de total aderência a OIT, 2008; 01 (um) considerado como parcialmente atendido e 05 (cinco) em desconformidade com o preconizado pela OIT, 2008. Um deles, "Trabalho a ser Abolido", não apresentou concordância de análise das respostas que permitissem ao pesquisador concluir o grau de aderência buscado.

\section{CONSIDERAÇÕES FINAIS}

A situação encontrada demonstra evolução em termos de condições materiais de trabaIho e valorização da carreira policial ao longo dos anos, havendo, todavia, ainda muito que evoluir em busca das condições ideais. O principal ponto de fragilidade é o diminuto efetivo de recursos humanos encontrado nas delegacias, o que repercute negativamente em quase todos os indicadores de trabalho especificamente pesquisados.

As mulheres pesquisadas revelaram percepção geral de desconformidade com os indicadores da OIT, ressalvando-se os critérios ligados à seguridade e diálogo social, bem como estabilidade e rendimentos adequados que foram considerados total ou parcialmente atendidos. Nos demais pontos, foram ressaltadas evidências muito significativas de que não há adequação do trabalho policial aos vetores do trabalho decente da OIT.

Os apontamentos mais relevantes estão relacionados à falta de atendimento de condições mínimas de segurança no ambiente de trabalho, seguidos do ambiente desfavorável à muIher em termos de igualdade e oportunidades. No mesmo passo, quando verificada a jornada de trabalho e a possibilidade de conciliar a atividade policial com a vida pessoal, foram destacados indicativos de maior prejuízo às mulheres.

Este estudo trouxe importante resultado, no sentido de transformar achados empíricos das realidades vivenciadas pelas servidoras em evidências científicas aptas a auxiliar a compreensão do trabalho policial. Em especial o trabalho da mulher na Polícia Civil revela um ambiente desafiador, com muitas dificuldades tanto para o exercício de um trabalho considerado decente pelas mulheres como pelos homens.

O estudo proporcionou ainda a observação do trabalho policial pela ótica científica, a partir de diversos doutrinadores e instituições, trazendo evidências relevantes sobre um tema bastante atual. Isso potencializará a possibilidade de serem realizados novos estudos com vista a alargar a compreensão sobre a temática e contribuir para estratégias de gestão mais focadas na sustentabilidade pelo viés da responsabilidade social, com vista ao bem estar dos colaboradores. 
O estudo pode subsidiar a Polícia Civil do RS no sentido de reavaliar e aprimorar seu ambiente de trabalho para o atendimento de critérios mais equânimes ao seus colaboradores, refletindo em práticas de responsabilidade social com ganhos internos e externos ao ambiente do trabalho policial.

\section{REFERÊNCIAS}

ALVES, D. B. Trabalho, educação e conhecimento na enfermagem: uma contribuição aos estudos sobre a força de trabalho feminina. Salvador: Dankat, 1997.

ALVESSON, M.; BILLING, I.D. Understanding gender in organizations. London: Sage, 1997.

BANDEIRA, L.; MELO, H. P. de. Memórias das lutas Feministas no Brasil. Secretaria de Políticas para as Mulheres. Presidência da República. Brasília: SPM, 2010.

BARDIN, L. Análise de conteúdo. Edição Revista e Actualizada. Lisboa: Edições 70, 2009.

BARZOTTO, L. C. Direitos humanos e trabalhadores. Porto Alegre: Livraria do Advogado, 2007.

BEAUVOIR, S. de. O Segundo Sexo. Tradução Sérgio Milliet. 2. ed. Rio de Janeiro: Nova Fronteira, 2009.

BETIOL, M. I. S. Ser administradora é o feminino de ser administrador? In: Encontro Nacional dos Programas de Pós-Graduação em Administração, 24, 2000, Florianópolis, Anais... ANPAD, 2000.

BEUREN, I. M. Como elaborar Trabalhos Monográficos em Contabilidade. 2.ed. São Paulo: Atlas, 2004.

BIANCHI, E. M. P. G.; QUISHIDA, A. Gestão Estratégica de Carreiras. In: ALBUQUERQUE, L. G.; LEITE, N. P. (Org). Gestão de pessoas perspectivas estratégicas. São Paulo: Atlas, 2009.

BORGES, L. de O.; TAMAYO, A. A estrutura cognitiva do significado do trabalho. Revista Psicologia, Organizações e Trabalho, Florianopolis, v. 1 n.2 , p. 11-44. 2001.

BRUSCHINI, C. "Teoria Crítica da Família”. In: AZEVEDO, M. A.; GUERRA, V. N. de A. (Org.). Infância e Violência Doméstica: fronteiras do conhecimento. 3a ed. São Paulo: Cortez Editora, 2000, p. 49-80.

BULOS, U. L.. Constituição Federal anotada. São Paulo: Saraiva, 2002.

CÁLAS, M. B.; SMIRCICH, L. Do Ponto de Vista da Mulher: Abordagens Feministas em Estudos Organizacionais. In: S. R. Clegg, C. Hardy, et al (Ed.). Handbook de Estudos Organizacionais. SP: Ed. Atlas, 1999.

CANOTILHO, J. J. G. Direito constitucional e teoria da constituição. 2.ed. Coimbra: Almedina, 1998.

CARVALHO NETO, A. M.; TANURE, B.; ANDRADE, J. Executivas: carreira, maternidade, amores e preconceitos. RAE - Eletrônica, v. 9, n. 1, art. 3, jan./jun., 2010.

ELKINGTON, J. A teoria dos três pilares. Tradução de Patrícia Martins Ramalho. São Paulo: Markron Books, 2001. Sustentabilidade: canibais com garfo e faca. São Paulo: Markron Books do Brasil, 2012.

ENGELS, F. Os diferentes ramos da indústria. In: A situação da classe trabalhadora na Inglaterra. São Paulo: Global, 1985. 
ETHOS. Institute. (2012). RSC. Responsabilidade social corporativa. Disponível em: http://www1. ethos.org.br/EthosWeb/pt/29/o_que_e_rse/o_que_e_rse.aspx. Acesso em 17 out. 2016.

GHAI, D. Trabajo decente: concepto e indicadores. Revista Internacional del Trabajo, v. 122, n.. 2, p. 125-160, 2003.

GOSDAL, T. C. Dignidade do trabalhador: um conceito construído sob o paradigma do trabalho decente e da honra. São Paulo: LTr., 2007.

GROSSI, M. P. Identidade de gênero e sexualidade. Antropologia em 1a mão. Florianópolis, UFSC/ PPGAS, 1998.

INSTITUTO ETHOS. Disponível em: http://www3.ethos.org.br. Acesso em 27 de out. 2015.

. Indicadores Ethos de Responsabilidade Social Empresarial. Coordenação da versão 2007 de Ana Lucia de Melo Custódio e Renato Moyal. São Paulo: Instituto Ethos, 2007.

- O compromisso das empresas com a igualdade racial. Benjamim S. Gonçalves (coordenação e edição). São Paulo: Instituto Ethos, 2006.

O Compromisso das Empresas com o Meio Ambiente - a Agenda Ambiental das Empresas e a Sustentabilidade da Economia Florestal / Benjamin S. Gonçalves (coordenação e edição). São Paulo: Instituto Ethos, 2005.

. O que as empresas podem fazer pela criança. Instituto Ethos de Empresas e Responsabilidade Social; Fundação Abrinq pelos Direitos da Criança. São Paulo: Instituto Ethos, 2000.

JUNQUEIRA, L. A. P.; MAIOR, J. S.; PINHEIRO, F. P. Sustentabilidade: a produção científica brasileira entre os anos de 2000 e 2009. Revista de Gestão Social e Ambiental. São Paulo, v. 5, n. 3, p. 36-52, set./dez. 2011.

LABUSCHAGNE C.; BRENT, A. C. Sustainable project life cycle management: the need to integrate life cycles in the manufacturing sector. International Journal of Project Management, v. 23, n. 2, p. 159-168, 2005.

LABUSCHAGNE, C.; BRENT, A. C.; ERCK, R. P. G. van Assessing the sustainability performances of industries. Journal of Cleaner Production, p. 1-13, 2004. Disponível em: <www. sciencedirect. com>. Acesso em 18 de fev. 2015.

LIMONGI-FRANÇA, A. C.; RODRIGUES, A. L. (2012). Stress e trabalho: uma abordagem psicossomática. 3 ed., São Paulo: Atlas, 2012.

MARQUES, A. L.; BORGES, R. S. G.; ADORNO, R. D. A LDB/96 e a qualidade de vida no trabalho: com a palavra os docentes da rede pública de belo horizonte. Revista de Ciências da Administração. Florianópolis, v. 10, n. 20, p. 72-94, jan./abr. 2008

MELO NETO, F. P. de; FROES, C. Responsabilidade Social e Cidadania Empresarial: a administração do terceiro setor. Rio de Janeiro: Qualitymark, 1999.

MENDES, G. F.; COELHO, I. M.; BRANCO, P. G. G. Curso de direito constitucional. 5. ed. São Paulo: Saraiva, 2010. 
MERINO, L. T. A eficácia do conceito de trabalho decente nas relações trabalhistas. Tese de doutorado. Disponível em:

MORAES, A. de. Direito constitucional. São Paulo: Atlas, 2004.

Direito Constitucional. 11. ed. São Paulo: Atlas, 2002.

Direito Constitucional. 16. ed. São Paulo: Atlas, 2004.

MORAES, R. Análise de conteúdo. Educação. Porto Alegre, v. 22, n. 37, p. 7-32, mar. 1999.

NERY JUNIOR, N. Princípios do processo civil na constituição federal. 5. ed. rev. e ampliada. São Paulo: Revista dos Tribunais, 1999. p. 42-50.

OIT (ORGANIZAÇÃO INTERNACIONAL DO TRABALHO). Disponível em: <http://www.oitbrasil.org. br/content/hist\%C3\%B3ria>. Acesso em 26 de out. 2015.

PAMPLONA, R. F. “Orientação Sexual e Discriminação no Emprego", São Paulo, LTr Editora, 2000.

PENA, R. P. M. Responsabilidade social da empresa e business ethics: uma relação necessária? ENCONTRO ANUAL DOS PROGRAMAS DE PÓS-GRADUAÇÃO EM ADMINISTRAÇÃO - ENANPAD, 27., 2003, Atibaia. Anais eletrônicos... Atibaia: Anpad, 2003.

PIOVESAN, F.; IKAWA, D. A violência doméstica contra a mulher e a proteção dos direitos humanos. In: Direitos humanos no cotidiano jurídico, 2004.

PIOVESAN, F. Direitos humanos e o direito constitucional internacional. 4ed. São Paulo: Max Limonad, 2000.

PRONI, M. W. Trabalho decente e vulnerabilidade ocupacional no Brasil. Revista Economia e Sociedade, Campinas: v. 22, n.3. 2013.

SARLET, I. W. A eficácia dos direitos fundamentais. 2a ed. Porto Alegre: Livraria do Advogado, 2001.

SCOTT, J. W. Gênero: uma categoria útil de análise histórica. Educação \& Realidade. Porto Alegre, v. 20, n 2, p. 71-99, jul./dez. 1995,.

SROUR, R. H. Ética empresarial: posturas responsáveis nos negócios, na política e nas relações pessoais. Rio de Janeiro: Campus, 2000.

TOURAINE, A. Após a Crise: a decomposição da vida social e o surgimento de atores não sociais. Petrópolis, RJ: Vozes, 2011.

TRIVIÑOS, A. N. S. Introdução à Pesquisa em Ciências Sociais: a pesquisa qualitativa em educação. São Paulo: Atlas, 2007.

UNIFEM E PACTO GLOBAL DAS NAÇÕES UNIDAS. Princípios de Empoderamento das Mulheres Disponível em: <http://www.unifem.org.br/003/00301009.asp?ttCD_CHAVE=119216>. Acesso em: 22 de set. 2015.

WALTON, R. E. Quality of working life: what is it? Slow Management Review, Cambridge, v. 15, n. 1, p. 11-21, 1973 